\title{
CONTROLLING AND MONITORING WATER DISTRIBUTION SYSTEM USING SENSORY NETWORK
}

\author{
Mr. Hemant K. Shete \\ Asst. Professor, Department of Mechanical \\ Dr. Daulatrao Aher College of Engg. \\ Karad, Maharashtra, India
}

\author{
Mr. Sanket V. Raut, Mr. Harshad S. Deshmukh, Mr. Pravin J. Mane Mr.Rohit S. Pawar, Mr. Abhijeet S. Jadhav \\ Student \\ Department of Mechanical \\ Dr. Daulatrao Aher College of Engg. \\ Karad, Maharashtra, India
}

\begin{abstract}
Water distribution systems present a significant challenge for monitoring. They comprise a complex network of pipelines that are difficult to access. There is a need for, on-line monitoring and control of water distribution systems in order to facilitate efficient management and operation. In particular, it is important to detect and localize pipe failures such as leakage, no uniform pressure and flow soon after they occur, and identify areas of the distribution network that are more likely to be susceptible to failure. These capabilities are vital for reducing the time taken to identify and repair failures and hence, minimize impacts on water supply.
\end{abstract}

The key concept of system is to plan a low cost proficient system to accomplish better water supply by controlling and supervising it from a mobile to eliminate problems in the supply of water. Arduino is minicomputer in this system design with water flow sensor, and solenoid valves. Arduino is utilized to control the valve and flow meter. System will take care of the issue of overflow, leakage detection, monitoring of water pressure and flow makes an appropriate.

Keywords - Arduino, Water flow sensor, Solenoid valve

\section{INTRODUCTION}

Water Distribution Systems (WDS) supplies potable water to industrial, commercial and residential consumers from water sources (reservoirs, water tanks) through distribution pipe networks. This WDS should supply water to perform many daily tasks, and controlled water supply through planned maintenance or leakage repairs can cause significant problems.
Urban water is provided to the habitats with the assistance of labor. The individual labor in control will go to the place and afterward open the valve to that specific territory. Once the time is over the individual will go again to that place and close the valve. This sort of activity needs labor.

In the market, for monitoring of water distribution we have different methods or systems, but they are very expensive. They use PLC or SCADA to monitor distribution. The cost of PLC's and different sensors make the system very expensive. So to minimize the cost and make it easily available for small industries. We are used Arduino as microcontroller and low cost sensor to develop smart network.

As mentioned proposed design utilizes an Arduino as minicomputer, water flow sensor, and solenoid valves. Arduino is utilized to control the valve and flow meter. The proposed design will monitor the overflow from source, controlled water flow rate with adequate pressure and will display online condition of each control valve.

\subsection{Advantages}

- Manual work is minimized by automation.

- Due to automation manpower is reduced.

- Detection of failure of system.

- To control flow.

- Less expensive

\subsection{Applications}

- Water Distribution in big structures, in agriculture field

- In irrigation 
- In petroleum system

- Small scale industries

\section{Block DiAGRAM}

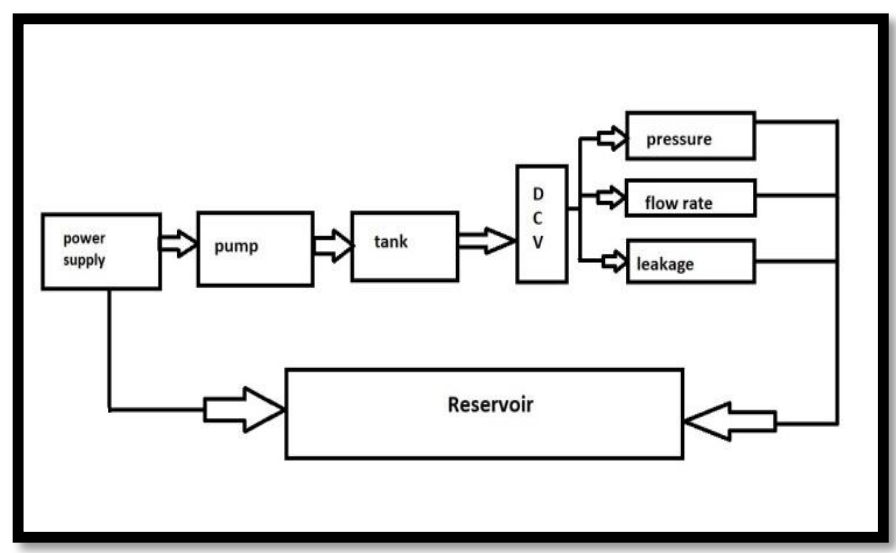

Fig 1. Block Diagram

As per fig. 1 mentioned block diagram a prototype model is depicted as shown, includes different components such as direction control valve (DCV)-which select particular pipe for water supply, DCV is feed with water through storage tank of controlled water level system. DCV will select particular pipe with of difference in flow, water pressure and leakage test. This model is constructed using different components mentioned as below.

\section{COMPONENTS}

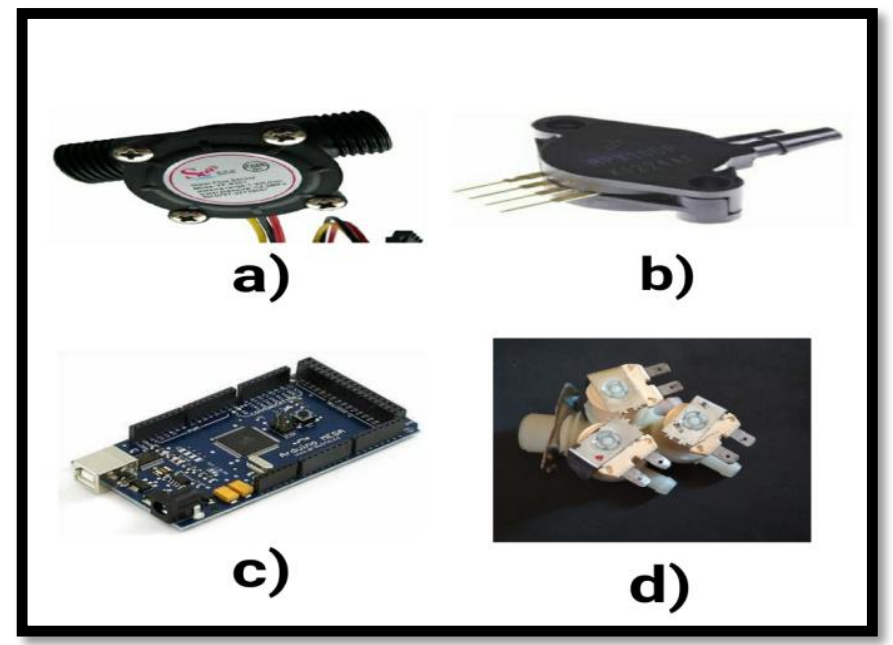

a) Flow Rate valve

Fig 2. Components

Fluid flowmeters are available with different working principles and classified as- Orifices, Vortex, Nozzles, Rotameters, Pitot Tubes, Calorimetric, Turbine, Venturies, Electromagnetic, Doppler, Ultrasonic, Thermal and Coriolis.
In this project, turbine type flow meter is selected as it is very cheap and its accuracy is also best. In these flow rate valve magnet is present. If magnet revolves one rotation then it gives one pulse to Arduino board if it revolves second rotation then it gives second pulse. As the flow increases no of revolutions increases also no of pulses increases. Arduino counts the no of pulses and decides the flow rate.

\section{b) Pressure Sensor}

The name of these pressure sensor is MPX 10DP. This is differential type pressure sensor. It has two ports one is vacuum port and another is pressure port. Vacuum pressure is considered as reference pressure. Actual pressure is applied to second port that is pressure port. Difference between two pressures is monitored. The differential signal is generated.

\section{c) Arduino}

In the market there are different types of Arduino boards used for different applications. This system needs large number of input output ports, for that purpose Arduino Mega is perfect.

The Arduino Mega 2560 is a microcontroller board based on the ATmega2560. It has 54 digital input/output pins (of which 15 can be used as PWM outputs), 16 analog inputs, 4 UARTs (hardware serial ports), a $16 \mathrm{MHz}$ crystal oscillator, a USB connection, a power jack, an ICSP header, and a reset button.

It contains everything needed to support the microcontroller; simply connect it to a computer with a USB cable or power it with an AC-to-DC adapter or battery to get started.

\section{d) Three way Direction control Valve}

DCVs are one of the most fundamental parts of hydraulic and pneumatic systems. DCVs allow fluid flow (hydraulic oil, water or air) into different paths from one or more sources. DCVs will usually consist of a spool inside a cylinder which is mechanically or electrically actuated. The position of the spool restricts or permits flow, thus it controls the fluid flow. They are widely used in the hydraulics industry. These valves make use of electromechanical solenoid for sliding of the spool. Control of these valves is done through simple application of electrical power, these valves are commonly in use.

\section{e) Water Level Indicator}

This system consists of two water level indicators. One is connected at bottom position of tank and another is connected at top position of tank. The principle behind this is "when there is no water in tank, pump is automatically ON and water is present at any one of the sensor the pump is OFF". 


\section{DESIGN OF SYSTEM}

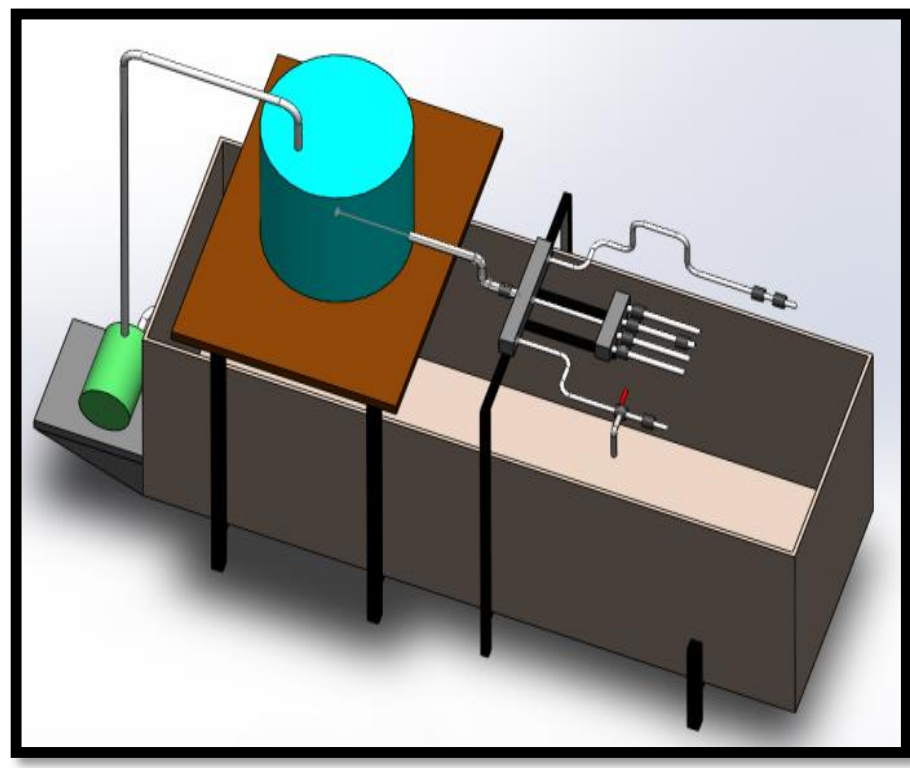

Fig 3. Three dimensional view

\section{WEBPAGE}

The output from system is monitored from app as well as LCD display. We developed the app by using MIT app developer. This app is connected with Bluetooth module. The range of Bluetooth module is 2.45 gigahertz. Using graphical interfacing data transmitted by Bluetooth module in the binary code. By activating the app arduino works as per program stored and system works through 4 relays. The design of app is shown below.

\section{Description of display}

The display consist of status of each line along with flow rate and pressure, it also shows condition of storage tank pump which controls the level in storage tank

Control buttons are provided on the screen for turning on and off of each line so that we can remotely control the flow through each line. The app is user friendly so any one can control and monitor the flow through each distributing pipe line.

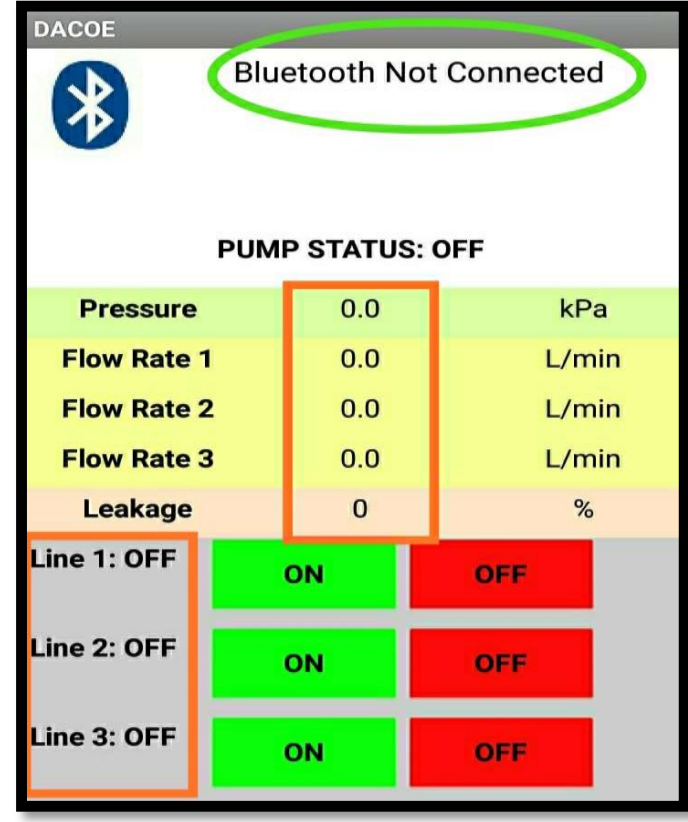

Fig 4. Initial Display

As shown in figure, shows status of all the parameters received from different sensors along with this it shows status of each pipeline. Currently it shows all lines are off hence no any feedback from respective sensor.

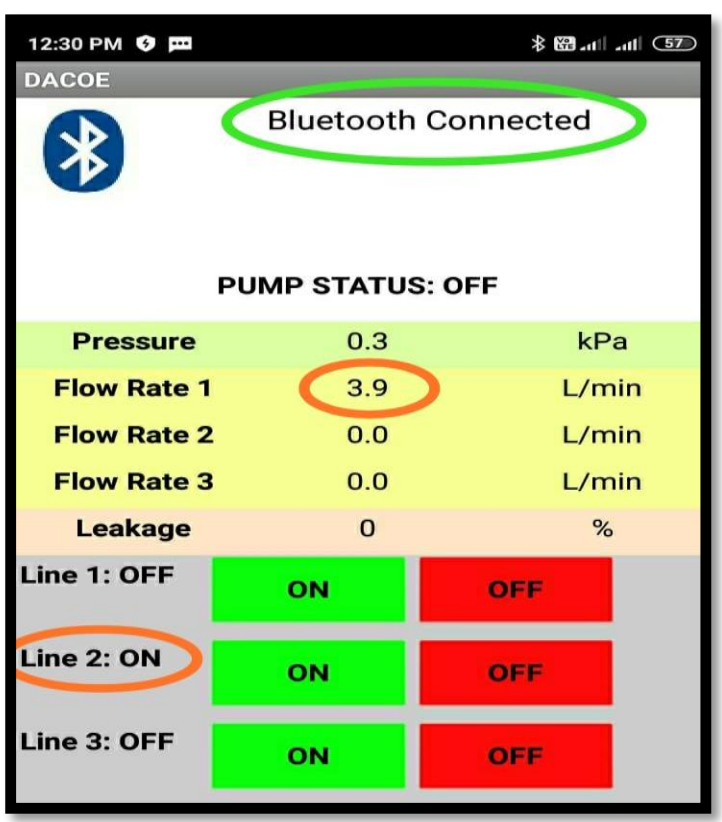

Fig 5. Display after flow through first line

If first line made on then flow rate can be observed on line1 and also it shows input pressure too shown in figure 5 


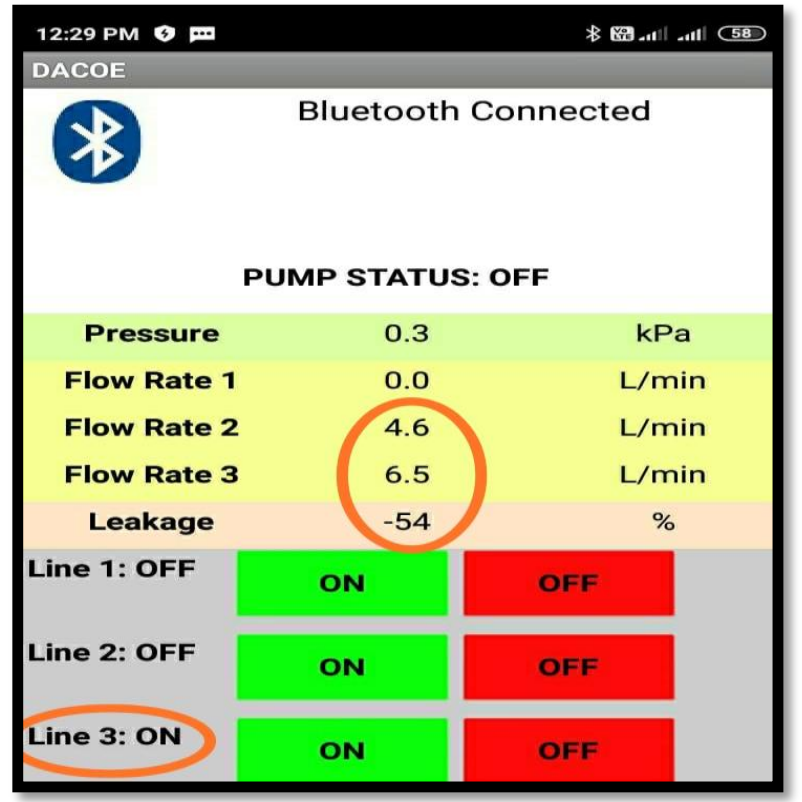

Fig 6. Display leakage through line 3

As shown in figure Line 3 is on where there is a leakage in the pipe line at the rate 6.5 lit./min. Also it shows pressure of $0.3 \mathrm{kPa}$

\section{CONCLUSION}

This system monitor and control the in and out flow of tank using sensors. This model can measure various parameters such as flow rate of specific pipelines and pressure as well. If there will be any leakage in pipe, then due to flow rate difference the leakage may identify before it will make losses to system. The display screen shows that the percentage leakage in the pipe. This will useful in any industry where hydraulic systems are in used.

As whole system having simple sensors and Arduino board system is very low cost and useful. As whole parameters can be observed and monitored through mobile via Bluetooth, it is conveniently and continuously monitor water distribution system.

\section{REFERENCE}

[1] Adamo, F., Attivissimo, F., Guarnieri, C., Carducci, C., Maria, A., \& Lanzolla, L. (2015). . pp. 2514-2522. "A smart sensor network for sea water quality monitoring" (Vol. 15(5)).

[2] Zhu, X., Li, D., He, D., Wang, J., Ma, D., \& Li, F. (2010). "A remote wireless system for water quality online monitoring in intensive fish culture" Computers and Electronics in Agriculture, 71(Suppl. 1), 3-9. Yue, R., \& Ying, T. (2012). "A novel water quality monitoring system based on solar power supply \& wireless sensor network" Procedia Environmental Sciences, 12(Icese 2011), 265-272.

[3] Sridharan, S. (2014). "Water quality monitoring system using wireless sensor network" International Journal of Advanced Research in Electronics and Communication Engineering (IJARECE), 3(4), 399-402.

[4] Rasin, Zulhani, Abdullah, Mohd Rizal, " Water Quality Monitoring System Using Zigbee Based Wireless Sensor Network" International Journal of Engineering \& Technology;Dec2009, Vol. 9 Issue 10, p24.

[5] Kirankumar G.Sutar , Prof.Ramesh T.Patil ," Wireless Sensor Network System to Monitor The Fish Farm" - Int. Journal of Engineering Research and Applications Vol. 3, Issue 5, Sep-Oct 2013, pp.194-197.

[6] Shruti Sridharan, "Water Quality Monitoring System Using Wireless Sensor Network" - International Journal of Advanced Research in Electronics and Communication Engineering (IJARECE) Volume 3, Issue 4, April 2014.

[7] R.Karthik Kumar, M.Chandra Mohan, S.Vengateshapandiyan, M.Mathan Kumar, R.Eswaran, " Solar based advanced water quality monitoring system using wireless sensor network " - International Journal of Science, Engineering and Technology Research (IJSETR), Volume 3, Issue 3, March 2014 ISSN: 2278 - 7798.

[8] Daudi S. Simbeye and Shi Feng Yang, "Water Quality Monitoring and Control for Aquaculture Based on Wireless Sensor Networks" - Journal Of Networks, VOL. 9, NO. 4, APRIL 2014.

[9] M. H. FotouhiGhazvnii, M. Vahabi, M. F. A. Raised and R. S. A. Raja Abdullah, "Energy Efficienc in M 802.15.4for Wireless Sensor Networks," Proceedings of IEEE 2008 6th National Conference on Telecommunication Technologies and IEEE 2008 2nd Malaysia Conference on Photonics, Putrajya, Malaysia, Aug., 2008, pp. 289-294.

[10] Shifeng Fang, LiDaXu. An Integrated System for Regional Environmental Monitoring and Management Based on Internet of Things[J], Ieee Transactions On Industrial Informatics, VOL. 10, NO. 2, MAY 2014, PP:1596-1605.

[11] Rao,A.S.,Marshall,S.,Gubbi,J.Palaniswami,(2013)"Desig $\mathrm{n}$ of Low-cost Autonomous Water Quality Monitoring System".2013 International Conference on Advances in Computing CommunicationsandInformatics(ICACCI), Mys or e,22-25 August 2013,14-19.

[12] Jiang, P., Xia, H., He,Z.,\&Wang,Z.(2009). Design of a water environmentmonitoring system based on wirelesssensor networks. Sensors, 9(8), 6411-6434.

[13] Biedugnis, S., \& Czapczuk, A. (2018). The application of the 'K-nearest neighbour' method to evaluate pressure loss in water supply lines. Technical Transactions, 
Published Online May 2020 in IJEAST (http://www.ijeast.com)

115(1), 141-149, doi: 10.4467/2353737XCT.18. 011.7962.

[14] Yue, R., \& Ying, T. (2012). "A novel water quality monitoring system based on solar power supply \& wireless sensor network" Procedia Environmental Sciences, 12(Icese 2011), 265-272. 